\title{
Attribution-based motivation treatment efficacy in an online learning environment for students who differ in cognitive elaboration
}

Article

Accepted Version

Hamm, J. M., Perry, R. P., Chipperfield, J. G., Murayama, K. and Weiner, B. (2017) Attribution-based motivation treatment efficacy in an online learning environment for students who differ in cognitive elaboration. Motivation and Emotion, 41 (5). pp. 600-616. ISSN 1573-6644 doi:

https://doi.org/10.1007/s11031-017-9632-8 Available at https://centaur.reading.ac.uk/72219/

It is advisable to refer to the publisher's version if you intend to cite from the work. See Guidance on citing.

To link to this article DOI: http://dx.doi.org/10.1007/s11031-017-9632-8

Publisher: Springer

All outputs in CentAUR are protected by Intellectual Property Rights law, including copyright law. Copyright and IPR is retained by the creators or other copyright holders. Terms and conditions for use of this material are defined in the End User Agreement. 


\section{www.reading.ac.uk/centaur}

\section{CentAUR}

Central Archive at the University of Reading

Reading's research outputs online 


\begin{abstract}
Attribution-based Motivation Treatment Efficacy in an Online Learning Environment for Students Who Differ in Cognitive Elaboration
\end{abstract}

\author{
Jeremy M. Hamm \\ University of California, Irvine \\ Raymond P. Perry, \& Judith G. Chipperfield \\ University of Manitoba
}

\author{
Kou Murayama \\ University of Reading
}

Bernard Weiner

University of California, Los Angeles

This is a pre-copyedited, author-produced PDF of an article accepted for publication in Motivation and Emotion following peer review.

\title{
Citation:
}

Hamm, J. M., Perry, R. P., Chipperfield, J. G., Murayama, K., \& Weiner, B. (in press). Attribution-based motivation treatment efficacy in an online learning environment for students who differ in cognitive engagement. Motivation and Emotion. doi:10.1007/s11031-017-9632-8 


\begin{abstract}
Attribution-based motivation treatments can boost performance in competitive achievement settings (Perry \& Hamm, 2017), yet their efficacy relative to mediating processes and affectbased treatments remains largely unexamined. In a two-semester, pre-post, randomized treatment study $(n=806)$, attributional retraining $(\mathrm{AR})$ and stress-reduction $(\mathrm{SR})$ treatments were administered in an online learning environment to first-year college students who differed in cognitive elaboration (low, high). Low elaborators who received AR outperformed their SR peers by nearly a letter grade on a class test assessed five months post-treatment. Path analysis revealed this AR-performance linkage was mediated by causal attributions, perceived control, and positive and negative achievement emotions in a hypothesized causal sequence. Results advance the literature by showing AR (vs. SR) improved performance indirectly via cognitive and affective process variables specified by Weiner's (1985a, 2012) attribution theory of motivation and emotion.

Keywords: attribution-based motivation treatment, perceived control, achievement emotions, performance
\end{abstract}


Attribution-based Motivation Treatment Efficacy in an Online Learning Environment for Students Who Differ in Cognitive Elaboration

Life course transitions occur at regular intervals throughout human development and are often fraught with challenge and adversity. During these shifts, individuals strive to master uncertainty and unpredictability by balancing transition-related goals with context-specific demands as experienced when entering a new school, starting a career, having a first child, moving to another city, or retiring (Heckhausen, Wrosch, \& Schultz, 2010; Perry, 2003). Ubiquitous among these experiences are school-to-university transitions that feature novel learning environments, heightened academic competition, frequent failure, increased financial demands, and unstable social networks that deter young adults' academic development (Perry, 2003; Perry, Hall, \& Ruthig, 2005).

Recent data show nearly $30 \%$ of students enrolled in U.S. universities drop out within the first year and fewer than 60\% graduate after six years (Snyder \& Dillow, 2013; see also Barefoot, 2004; Feldman, 2005; Tinto, 2010). Similar dropout rates have been reported by the European Union (Directorate General for Education and Culture, European Commission, 2015) and the Organisation for Economic Co-Operation and Development (OECD) based on data from its member countries in North America, South America, Europe, Asia, and Australia (OECD, 2012).

These findings suggest transition-related challenges can overwhelm even highly motivated students and culminate in academic failures that initiate a protracted search to explain the causes of such important, negative, and unexpected events (Stupnisky, Stewart, Daniels, \& Perry, 2011; Weiner, 1985a, Wong \& Weiner, 1981). Although these causal explanations (i.e., attributions) may occur rapidly and spontaneously, the consequences for subsequent cognitions, emotions, motivation, and goal attainment can be significant (Weiner, 1985b, 2012). A 
comprehensive field study of school-to-university transitions involving five separate longitudinal cohorts of first-year students ( $n>3,000$; Perry, Stupnisky, Daniels, \& Haynes, 2008) shows that causal attributions have demonstrable consequences for long-term adjustment. Students who endorsed controllable (vs. uncontrollable) attributions for poor performance reported higher expectations of future success and less helplessness, shame, and anger over a five-month period. They also had higher final course grades and better cumulative grade point averages (GPAs) across all courses at the end of their first year.

Capitalizing on these and other studies in both laboratory and field settings (e.g., Perry \& Magnusson, 1989; Van Overwalle, Mervielde, \& De Schuyter, 1995; Zhou \& Urhahne, 2013), attribution-based interventions have been designed to encourage controllable (e.g., insufficient effort) rather than uncontrollable (e.g., limited ability) attributions for performance outcomes during life course transitions. These attributional retraining (AR) treatments consistently show that AR recipients outperform their no-AR peers on post-treatment achievement outcomes that range from class tests assessed after several weeks to year-end cumulative GPAs assessed after 12 months (see Haynes, Perry, Stupnisky, \& Daniels, 2009; and Perry, Chipperfield, Hladkyj, Pekrun, \& Hamm, 2014 for reviews). A recent meta-analysis by Lazowski and Hulleman (2016) showed AR treatment effects are typically moderate in size $(d=0.54)$ and translate into performance gains of one to two letter grades (see Perry et al., 2014; Perry \& Hamm, 2017). However, the efficacy of AR treatments relative to mediating processes and other evidencebased interventions remains unexamined.

Our study addressed this omission using a two-semester, pre-post, randomized treatment field design that assessed whether a cognitive AR treatment (vs. affective stress-reduction treatment) improved academic adjustment when administered online to first-year students who 
differed in cognitive elaboration (low, high). In so doing, our study also advanced the literature by assessing whether AR treatment efficacy was mediated by an attribution-cognition-emotion sequence implied by Weiner's attribution theory of motivation (1985a, 2006, 2012).

\section{Attributional Retraining and Goal Striving}

Laboratory and quasi-experimental field studies have sought to address the internal, external, and ecological validity of attribution-based treatment efficacy for young adults in competitive achievement settings (cf., Cook \& Campbell, 1979; Shadish, Cook, \& Campbell, 2002; Tunnell, 1977). Early AR research emphasized internal validity and was conducted in highly controlled laboratory settings that simulated classroom learning conditions. Results of these randomized treatment studies showed that college students who received AR (vs. no-AR) performed better on achievement tests based on GRE items, lecture material, and homework assignments assessed immediately following the treatment or one week post-treatment (Menec, Perry, Struthers, \& Schönwetter, 1994; Perry \& Magnusson, 1989; Perry \& Penner, 1990; Perry, Schönwetter, Magnusson, \& Struthers, 1994).

Quasi-experimental field studies extended the assessment of AR-performance linkages beyond the laboratory to address issues involving external and ecological validity in competitive achievement settings. Randomized treatment field studies informed by Weiner's attribution theory of motivation showed that AR (vs. no-AR) facilitated performance on individual class tests and overall course grades assessed up to six months post-treatment (e.g., Boese, Stewart, Perry, \& Hamm, 2013; Parker, Perry, Hamm, Chipperfield, \& Hladkyj, 2016; Perry, Stupnisky, Hall, Chipperfield, \& Weiner, 2010; Perry \& Struthers, 1994). Field studies also demonstrated that recipients of AR (vs. no-AR) were less likely to fail year-end final exams and entire courses (Haynes-Stewart et al., 2011; Van Overwalle \& Metsenaere, 1990). Consistent evidence has 
shown students who received AR earned significantly higher cumulative, year-end GPAs up to 12 months post-treatment relative to their no-AR peers (e.g., Hamm, Perry, Clifton, Chipperfield, \& Boese, 2014; Haynes, Ruthig, Perry, Stupnisky, \& Hall, 2006; Perry et al., 2010; Wilson \& Linville, 1982). These achievement effects translate into increases of one or more letter grades for $\mathrm{AR}$ recipients, depending on the grading practices in a given course or institution (see Perry et al., 2010, 2014; Perry \& Hamm, 2017).

An important qualification emerging from this research is that AR treatments may only increase performance under some learning conditions and for certain individuals (see Perry et al., 2014). AR treatment efficacy appears to be optimal under conditions involving transitions to novel and unpredictable achievement settings that commonly result in increased failure and that trigger a search for the causes of these negative events (Haynes et al., 2009; Perry, Hall, et al., 2005). Individuals more likely to benefit from AR treatments are those who have greater difficulty adapting to adverse learning conditions common to competitive achievement settings (Haynes et al., 2009; Perry, 2003). Thus, the present study examined whether AR benefits firstyear students who have low levels of cognitive elaboration, and, as a consequence, may struggle to adapt to the rigorous learning requirements imposed during the transition to university.

\section{Attributional Retraining and Cognitive Elaboration}

Empirical evidence suggests there are negative consequences for young adults who fail to employ deep processing approaches to learning in postsecondary achievement settings (Richardson, Abraham, \& Bond, 2012). Cognitive elaboration represents one such deep processing approach that involves a relatively stable tendency to assimilate novel information with existing knowledge (Entwistle, 2000; Pintrich, Roeser, \& De Groot, 1994; Pintrich, Smith, Garcia, \& McKeachie, 1993; see also Richardson et al., 2012). Low levels of cognitive 
elaboration are related to less critical thinking (Pintrich et al., 1993), lower expectations of future success (Hall et al., 2007), reduced perceived control (Pintrich et al., 1993), decreased intrinsic motivation (Perry, Hladkyj, Pekrun, \& Pelletier, 2001), and maladaptive achievement emotions such as less enjoyment and more boredom (Pekrun, Goetz, Titz, \& Perry, 2002). Infrequent use of elaboration strategies also undermines final course grades and cumulative, year-end GPAs (Hall et al., 2004, 2007; Phan, 2010; Perry et al., 2001; Richardson et al., 2012). Research by Hall et al. (2007) showed low elaborators $(M=2.59)$ attained cumulative GPAs that were approximately half a letter grade lower than their high elaborator peers $(M=2.88)$ over a sixmonth period.

Noteworthy is that Weiner's (1985a, 2012) construal of causal search suggests conceptual parallels to cognitive elaboration. Weiner posits that causal search constitutes a subjective appraisal process to determine the causes of success or failure. Not unlike cognitive elaboration, causal search involves attending to circumstances that led to the outcome, integrating pertinent situational information, and specifying factors that contributed to the outcome. This implies that causal search and cognitive elaboration processes share similarities in that both involve the appraisal of context-relevant details and the deep processing of information encountered in novel learning environments. For instance, causal search depends on (a) being aware of relevant, possible determinants of an outcome and (b) deeply reflecting on this information so as to come to a meaningful understanding of the circumstances. Similarly, cognitive elaboration requires (a) being aware of relevant, existing knowledge and (b) deeply reflecting on how such knowledge relates to new information so as to understand and apply novel material.

AR treatments may benefit low elaborators given that they are designed to trigger an intensive appraisal process of the controllable causes of performance outcomes (causal search), 
which should serve to obviate the detriments of surface processing (low elaboration). The initial stage of the AR protocol occurs prior to the treatment video and is designed to remedy surface processing by encouraging recipients to deeply reflect on the causes of poor personal performance (i.e., engage in causal search). This is accomplished by administering the AR treatment video only after students have had time to process performance feedback on a class test at the start of the academic year. Immediately prior to receiving AR, students are also asked to rate the importance of various causal attributions for a previous unsatisfactory performance (Haynes et al., 2009; Perry et al., 2005, 2014). These treatment protocols initiate cognitive processes that facilitate deep processing of previous academic setbacks and thereby heighten receptiveness and engagement with treatment content (Perry \& Hamm, 2017).

The final stage occurs immediately following the AR treatment video and involves a writing procedure wherein students elaborate on the value of emphasizing controllable (and deemphasizing uncontrollable) attributions for poor performance. This stage seeks to achieve three goals related to elaborative processing: depth, by fostering interconnections of the content via summarization; breadth, by associating the content with a variety of related information; and personal meaning, by creating personally-relevant examples (Entwistle, 2000). Some evidence suggests that low elaborating university students who received AR reported fewer uncontrollable attributions and achieved higher final course grades post-treatment than their no-AR peers (Hall et al., 2004, 2007).

\section{Attributional Retraining Efficacy for Low Elaborators in Online Learning Environments}

Although consistent evidence shows AR treatment effects on academic performance are of appreciable magnitude (see Perry et al., 2014, 2017), several significant gaps remain in the literature. First, researchers have yet to conduct more stringent tests of AR treatment efficacy by 
assessing it in relation to other pertinent treatments administered in competitive achievement settings (i.e., a treatment-treatment experimental design). Stress-reduction (SR) treatments, for example, focus on affective processes and are a conceptually-based and empirically-supported alternative to AR that can promote academic performance for university students (Cameron \& Nicholls, 1998; Lumley \& Provenzano, 2003; Pennebaker, Colder, \& Sharp, 1990; Pennebaker \& Francis, 1996; see also Regehr, Glancy, \& Pitts, 2013). Lumley and Provenzano (2003) showed that students who received an SR treatment attained GPAs that were nearly one letter grade higher than students in a control group several months post-treatment $(M \mathrm{~s}=2.72$ vs. 2.34). Given that AR treatments typically produce comparable performance gains (one to two letter grades; e.g., Perry et al., 2010), research that compares the efficacy of AR as a cognitive treatment to SR as an affective treatment would advance the motivation treatment literature.

Second, researchers have largely neglected to examine how (psychological mechanisms) AR influences performance outcomes. Because AR is intended to directly impact causal attributions (see Perry et al., 2014; Perry, Hall, et al., 2005), students' attributions for performance should represent the most proximal of these processes. Supporting this rationale, a few studies suggest that AR recipients are more likely to emphasize controllable (effort, strategy) and de-emphasize uncontrollable (ability, teaching quality, test difficulty, luck) attributions posttreatment than their no-AR peers (Haynes et al., 2006; Perry et al., 2010).

According to Weiner (1985a, 2012), attributional changes should impact subsequent cognitive and affective outcomes. Preliminary research suggests that AR (vs. no-AR) fosters perceived control (Haynes et al., 2006; Parker et al., 2016) and achievement-enhancing emotions, including increased hope and pride, but reduced shame and helplessness (Hall et al., 2004; Hamm et al., 2014). Each of these psychological outcomes has been linked to academic 
performance in theoretically consistent directions (Perry et al., 2001, 2005, 2008; Weiner, 1985a, 2012). Collectively, this pattern of results implies that AR may encourage adaptive causal attributions; in turn, such attributions may facilitate perceived control and achievementenhancing emotions; and feeling in control and experiencing adaptive emotions may promote performance. However, past studies have yet to examine whether these psychological mechanisms account for (mediate) AR's effects on performance, and a systematic empirical analysis is needed to test this theorized causal sequence.

A third, related shortcoming in previous research is a lack of studies exploring indirect effects of AR on performance for failure prone young adults. Despite the fact that AR has been shown to improve academic performance for vulnerable first-year students (see Haynes et al., 2009; Perry et al., 2014; Perry, Hall et al., 2005) and that Weiner's (1985a, 2012) attribution theory posits AR-performance effects should be indirect through pertinent psychological mediators, research has yet to examine these predictions simultaneously. Further field studies employing longitudinal designs and appropriate statistical techniques (e.g., moderated mediation; see Hayes, 2013) are needed to establish whether AR indirectly promotes performance via theoretically proposed mediators (e.g., attributions, perceived control, emotions) for certain students who may be especially amenable to the treatment (e.g., low elaborators).

Finally, despite the potential benefits of mass administering AR treatments online (see Perry et al., 2014, 2017), their efficacy in such settings remains largely unexamined. Online administration of AR would be in keeping with current educational methods which require students to access course information online as part of blended learning courses, distance courses, or Massive Open Online Courses (MOOCs). Supporting the efficacy of delivering AR online, some studies have found treatment effects when administering AR using a variety of methods, 
including videotape presentations (e.g., Perry et al., 2010), printed documents (e.g., Haynes et al., 2006), and internet handouts (e.g., Hall, Perry, Ruthig, Haynes, \& Stupnisky, 2005). Research is needed to examine AR treatment efficacy when delivered via online learning environments rather than within the confines of classroom or laboratory settings. Observing treatment effects using such a technologically advanced online procedure that could be scaled up would further support the ecological validity of AR.

Our two-semester, pre-post, randomized treatment field study assessed the efficacy of an online AR treatment (vs. an online SR treatment) in assisting first-year students during the school-to-university transition. Building on past studies, AR recipients with low cognitive elaboration were expected to outperform their peers who received SR on a final class test. The AR-performance linkage was expected to be mediated by psychological process variables based on Weiner's attribution theory (1985a, 1995, 2006, 2012). We predicted that, for low elaborators: (a) AR (vs. SR) would increase the endorsement of controllable attributions and reduce the endorsement of uncontrollable attributions; (b) emphasis on these adaptive attributions would promote perceived control and emotional well-being; (c) enhanced perceived control would predict increased positive and decreased negative emotion; and (d) perceived control and the positive and negative emotions would predict year-end academic performance (see Figure 1).

\section{Method}

\section{Participants and Procedures}

The online, pre-post, quasi-experimental, randomized treatment field study was based on a sample of students $(n=806)$ enrolled in a research-intensive university in Western Canada. Students were native English speakers in their first year of university, with the majority being 17-18 year old (79\%) females (64\%). They were from multiple sections of a blended 
introductory psychology course and participated in the study as part of a class assignment. Data were collected at three time points over two academic semesters that spanned eight months.

At Time 1a (November), students completed the first online questionnaire using a secure website. Time $1 \mathrm{~b}$ (November) immediately followed the Time 1a questionnaire and involved the secure website randomly assigning students to one of two treatment conditions using automated software (Shadish et al., 2002): Students in the experimental section received the online AR treatment, whereas those in the comparison condition received an online SR treatment. At Time 2 (March), participants completed a second online questionnaire similar to the first questionnaire using the same secure website. At Time 3 (April), academic performance data for consenting students were collected from course instructors. Analyses were based on students with complete data who consented to their questionnaire and performance data being used for research purposes.

\section{Main Study Variables}

Cognitive elaboration (Semester 1, Time 1a). Students indicated the extent to which they used six elaborative learning strategies adapted from Pintrich, Smith, and McKeachie at Time 1a (1989; e.g., "I try to understand the material in this class by making connections between the readings and the concepts from the lectures"). Strategies were rated on a five-point scale $(1=$ not at all true, $5=$ completely true $; M=21.05, S D=4.47$, range $=9-30$, Cronbach's $\alpha$ $=.77)$. Cognitive elaboration was reassessed using the same scale at Time $2(M=21.20, S D=$ 4.32, range $=9-30$, Cronbach's $\alpha=.78$, test-retest $r=.53$ ). The present four-month, test-retest reliability of the elaboration measure $(r=.53)$ is consistent with previous research showing acceptable stability over time, $r=.59$ (Hall et al., 2004). See Table 1 for a summary of the study variables. ${ }^{1}$

\footnotetext{
${ }^{1}$ Supplemental analyses employed CFA models to examine whether the study scales exhibited measurement invariance over time (Rossell, 2012). Results of nested model comparisons showed the fit of configural (T1a and T2
} 
Online treatment (Semester 1, Time 1b). The attributional retraining (AR) and stressreduction (SR) treatments were administered online to individual students using the secure website immediately following the Time 1a questionnaire. Treatment implementation fidelity was achieved using a standardized delivery method. Treatments consisted of pre-recorded video presentations described below and were randomly administered using an automated software protocol that ensured uniform implementation.

The AR treatment protocol involved three stages administered during a one-hour session (see Perry et al., 2005, 2014, 2017). First, the causal search activation stage prompted students to deeply process the causes of their past achievement failures (i.e., engage in causal search). Activation was induced by having students consider and rate the importance of various causal attributions to poor academic performance, as well as by administering AR only after students had time to reflect on performance feedback from their first introductory psychology test. These two activation protocols are based on Weiner's attribution theory (1985a, 2012) and research showing causal search commonly occurs following failure outcomes (Stupnisky et al. 2011; Wong \& Weiner, 1981).

Second, the attributional induction stage required students to view a narrated, 15-minute presentation that focused on the grade-enhancing impact of making controllable attributions for achievement failures. Based on Weiner's attribution theory (1985a, 2012) and three decades of empirical evidence (see Perry et al., 2014, 2017), the narrated presentation suggested that (a) humans are motivated to understand the causes of important outcomes in their lives (e.g., exam failure), (b) the resulting attributions can be classified according to two causal dimensions

factor loadings unconstrained) and metric (T1a and T2 factor loadings constrained equal) invariance models did not differ for any of the study scales at $p<.05$. Thus, the cognitive elaboration, uncontrollable attributions, controllable attributions, perceived control, negative emotion, and positive emotion scales exhibited metric measurement invariance at $\mathrm{T} 1 \mathrm{a}$ and $\mathrm{T} 2$. 
comprising locus (internal vs. external) and controllability (controllable vs. uncontrollable), (c) these causal dimensions can be crossed to form a four-cell attribution matrix, and (d) university students who consistently make attributions that fall in the internal-controllable cell (e.g., poor study strategy, insufficient effort) improve their academic performance over time.

Third, the consolidation stage encouraged students to deeply process the AR content using a writing activity designed to promote cognitive elaboration (see Haynes et al., 2009). The focus of the activity was on attribution elaboration: Participants summarized the presentation and described how they could apply the main points of the presentation in their own lives.

Students receiving the stress-reduction (SR) treatment completed the same activation and consolidation activities as their peers in the AR condition. However, during the critical induction phase, those in the SR condition viewed a narrated presentation focusing on stress management strategies based on Ellis' rational-emotive therapy $(1977,1985,2001)$. This presentation suggested that (a) everyone experiences stress, (b) stress management can be learned, and (c) six different strategies (e.g., emotional expression) may prove effective in reducing personal stress. The treatment variable was coded categorically $(1=S R[n=229], 2=A R[n=577])$. Note that simple random assignment with unequal probabilities (see Alferes, 2012) was used to assign $70 \%$ of participants to the AR condition and $30 \%$ of participants to the SR condition at the request of the department head. This online automated random assignment procedure was employed because the study was part of a departmental initiative to provide AR to as many introductory psychology students as possible. Because our focus is on AR (vs. SR) treatment effects, we refer to the treatment variable as $A R$ hereon in to facilitate interpretation of the results. Several precautions were taken to ensure the ecological validity of the AR and SR treatment protocols based on recommendations by Tunnell (1977) and Lazowski and Hulleman 
(2016; see also Hulleman, Barron, Kosovich, \& Lazowski, 2016; Shadish et al., 2002).

According to Tunnell (1977) and Lazowski and Hulleman (2016), ecological validity of quasiexperimental field procedures must meet three criteria based on naturalness:

[1] natural treatments are naturally occurring events to which the participant is exposed (e.g., pedagogical practices, curriculum); [2] natural settings are those that are not perceived to be established for the purposes of research (e.g., almost any setting outside the laboratory; see Shadish et al., 2002); and, [3] natural behavior occurs on its own without experimental intervention (e.g., statewide mandated standardized tests). (Lazowski \& Hulleman, 2016, p. 5)

Based on this framework, our study conforms to all criteria. Regarding natural treatments, treatment content was designed to achieve ecological validity by incorporating material related to class lectures and textbook readings in the introductory psychology course. Treatments were also embedded in the course curriculum as an assignment, and the online video presentations were consistent with the course's online lecture format. Regarding natural settings, interventions were administered in the same online learning environment that students used to access their other course materials. This enabled students to view the online treatments in a natural setting (on campus or at home) rather than within an artificial laboratory environment. Regarding natural behavior, a primary outcome measure (class test performance) was developed and administered by the course instructor and therefore captured a naturally occurring behavior within the educational context. In contrast to alternative measures such as researcher-created achievement tests, course grades reflect an authentic and consequential performance outcome that predicts future educational attainment $(r=.48)$ and occupational status $(r=.33$; see Richardson et al., 2012; Strenze, 2007). 
Attributions for poor performance (Semester 2, Time 2). Students responded to the question, "When you do poorly in your introductory psychology course, to what extent do the following factors contribute to your performance?" by rating the influence of strategy, effort, ability, professor's quality of teaching, test difficulty, and luck. Time 2 ratings were provided on a 10 -point scale $(1=$ not at all, $10=$ very much so $)$. Although phenomenological differences exist between individuals, it is postulated that students generally interpret strategy and effort attributions as personally controllable and ability, teaching quality, test difficulty, and luck as not personally controllable (Weiner, 1985a, 2006).

Consistent with previous research (e.g., Hall et al., 2006), we created two attribution measures by separately summing students' ratings of controllable $(M=15.30, S D=3.23$, range $=$ 6-20, $r=.44)$ and uncontrollable attributions $(M=21.26, S D=6.82$, range $=4-38$, Cronbach's $\alpha$ $=.67)$. Students' causal thinking was assessed using the same controllable $(M=14.82, S D=3.34$, range $=7-20, r=.36$, test-retest $r=.37)$ and uncontrollable attribution measures at Time $1 \mathrm{a}(M=$ 21.23, $S D=6.72$, range $=4-40$, Cronbach's $\alpha=.63$, test-retest $r=.48$ ).

Perceived control (Semester 2, Time 2). Students indicated their agreement with four items from Perry et al.'s (2001) Perceived Academic Control scale at Time 2 (PAC; e.g., "I see myself as largely responsible for my performance throughout my college career”). Items were rated on a five-point scale $(1=$ strongly disagree, $5=$ strongly agree; $M=16.82, S D=2.48$, range $=9-20$, Cronbach's $\alpha=.75)$. Perceived control was assessed using the same scale at Time 1a $(M=17.03, S D=2.27$, range $=12-20$, Cronbach's $\alpha=.68$, test-retest $r=.54)$. The present four-month, test-retest reliability of the scale $(r=.54)$ is consistent with previous research showing acceptable stability over time, $r=.59$ (Perry, Hladkyj, et al., 2005).

Achievement emotions (Semester 2, Time 2). Students reported their hope, pride, 
helplessness, and shame after reading the following stem: "Indicate the extent to which each of the following describes how you feel about your performance in introductory psychology." Time 2 ratings were provided on a 10 -point scale $(1=$ not at all, $10=$ very much so $)$. Separate measures of positive (hope/pride; $M=13.39, S D=3.63$, range $=4-20, r=.63$ ) and negative (helplessness/shame; $M=6.42, S D=4.16$, range $=2-18, r=.65$ ) achievement emotions were created by summing valence relevant item-pairs consistent with previous research (Hamm, Perry, Chipperfield, Heckhausen, \& Parker, 2016). Positive $(M=13.22, S D=3.45$, range $=4-20, r$ $=.42$, test-retest $r=.60)$ and negative $(M=6.33, S D=4.12$, range $=2-18, r=.58$, test-retest $r$ $=.54$ ) emotions were assessed using the same measures at Time 1a.

Academic performance (Semester 2, Time 3). Consenting students' performance was measured using their grades (percentages) on a final class test in a two-semester introductory psychology course $(M=78.20, S D=13.73$, range $=22.50-100.00)$. Initial performance on a pretreatment (Semester 1 , Time 1a) class test on course material to date was also assessed $(M=$ $66.79, S D=13.72$, range $=15.00-97.50$, test-retest $r=.66)$. The six-month test-retest reliability $(r=.66)$ observed in our study is consistent with previous research showing that this performance measure exhibits acceptable stability over time (e.g., Pekrun, Hall, Goetz, \& Perry, 2014). Achievement data were collected from course instructors after the second semester concluded.

\section{Covariates}

High school grade (HSG; Time 1a). Self-reported HSG (percentage) was used as a proxy for actual high school achievement based on a strong relation between the two, $r=.84$ (Perry, Hladkyj et al., 2005; $1=50 \%$ or less, $10=91-100 \% ; M=7.90, S D=1.57$, range $=4-10$ ). Previous research shows that this self-report measure of HSG is a reliable and substantial 
predictor of post-secondary achievement, including final course grades, $r=.40-.54$; and GPAs, $r$ $=.52-.54$ (e.g., Perry et al., 2001, 2010; Perry, Hladkyj et al., 2005). Canadian universities use HSGs as the primary admission criterion rather than standardized entrance examinations (e.g., SATs, ACTs). Meta-analyses by Richardson et al. (2012) and Robbins et al. (2004) revealed that HSGs are the strongest traditional correlate of university GPAs ( $r \mathrm{~s}=.40$ to .41$)$ and predict university performance as well or better than SAT ( $r=.29$ to .37$)$ or ACT scores $(r=.37$ to .40$)$.

Age (Time 1a). Participants indicated their age using a 10-point scale $(1=17-18,10=$ older than 45). Because a large majority (79\%) of students indicated they were between the ages of 17 and 18 and since the first year of university represents a challenging life course transition for young adults (Barefoot, 2004; Feldman, 2005; Perry, 2003), age was dichotomized into two pertinent categories consistent with previous research (Hamm, Perry, Chipperfield, Stewart, \& Heckhausen, 2015; $1=17-18 ; 2=19$ and older $1.21, S D=0.41$, range $=1-2$ ).

Gender (Time 1a). Gender was coded categorically ( 1 =female, $2=$ male; $64 \%$ female $)$.

\section{Results}

A Treatment $x$ Elaboration design was used to test the hypotheses. Simple slope regression analyses assessed whether the AR (vs. stress-reduction [SR]) treatment influenced performance on a final class test in Semester 2 for low elaborators. A path analytic approach examined whether AR treatment effects on performance (for low elaborators) were mediated by a hypothesized sequence of psychological mechanisms based on Weiner (1985a, 2012; see Figure 1). Details concerning the path analysis are provided in describing the results. Consistent with previous treatment intervention studies in competitive achievement settings (e.g., Hamm et al., 2014; Haynes Stewart et al., 2011), high school grade, age, and gender were controlled in all analyses to account for the extraneous influence of these demographic factors on motivation and 
performance outcomes (see Richardson et al., 2012).

Standardized regression weights are reported for all effects with the exception of the treatment effects. Because the treatment variable is dichotomous, it has been left in its original metric $(1=S R, 2=A R)$ to enable valid interpretation (Hayes, 2013). Hence, AR treatment effects are partially standardized and represent the mean difference between the AR and SR conditions on the dependent measures reported in standard deviation units (e.g., the standard deviation difference between the treatment conditions on the uncontrollable attributions measure). Note that a partially standardized beta weight is conceptually analogous to Cohen's $d$. Thus, a partially standardized AR treatment effect $(\beta=-.33)$ on the uncontrollable attributions indicates that low elaborators who received AR had scores on this measure that were 0.33 of a standard deviation lower than their peers who received the SR treatment.

\section{Random Assignment to Treatment Conditions}

In keeping with quasi-experimental, randomized treatment design considerations (Shadish et al., 2002), students were randomly assigned to experimental conditions (AR, SR) using automated software. Using independent sample $t$-tests, we found no evidence that the AR and SR treatment conditions differed with respect to pre-treatment demographic (gender, age), psychosocial (cognitive elaboration, uncontrollable attributions, controllable attributions, perceived control, negative emotion, positive emotion), or performance (HSG, Test 1) variables at $p<.01$.

\section{Zero-Order Correlations}

Correlation coefficients provided a description of the unadjusted relationships between the main study variables (see Table 1). As expected, high school grade $(r=.42)$ and all psychological variables were related to students' performance on the T3 final class test. Pointing 
to the benefits of deep processing (and the detriments of surface processing), higher levels of T1a cognitive elaboration were related to the endorsement of more T2 controllable attributions $(r$ $=.15)$, increased T2 perceived control $(r=.10)$, higher T2 hope/pride $(r=.31)$, lower T2 helplessness/shame ( $r=-.13)$, and, ultimately, better academic performance in both high school $(r=.11)$ and university $(r=.13)$. T2 controllable and uncontrollable attributions displayed an interesting pattern wherein they were related to each other $(r=.12)$, T2 perceived control (respective $r \mathrm{~s}=.39$ and -.30$), \mathrm{T} 2$ positive $(r \mathrm{~s}=.26$ and -.08$)$ and negative $(r \mathrm{~s}=-.16$ and .28$)$ emotion, and $\mathrm{T} 3$ achievement $(r \mathrm{~s}=.10$ and -.16$)$ in theoretically expected directions. Finally, T2 positive and negative emotion were strongly related to each other $(r=-.53)$ and T3 academic performance (respective $r s=.43$ and -.42 ).

\section{Simple Treatment Effects}

A Treatment x Elaboration regression model extended previous efficacy research by assessing whether low elaborators who received AR outperformed their SR treatment peers on a final class test in Semester 2. Predictors involved in the hypothesized interaction (treatment, cognitive elaboration) were mean centered, and all variables were simultaneously entered into the regression model. The hypothesized Treatment $x$ Elaboration interaction was observed $[\beta=-$ $.08, p=.016, \mathrm{CIs}=-0.138$ to -0.014$]$. The interaction was probed by testing simple treatment effects (slopes) at low (-1 SD) and high (+1 SD) levels of elaboration using the lavaan package for R (Cohen, Cohen, West, \& Aiken, 2003; Hayes, 2013; Rosseel, 2012). A priori, one-tailed tests were used to assess the directional prediction that low elaborators in the AR treatment condition would outperform their peers in the SR treatment condition.

Simple slope regression analyses showed that low elaborators in the AR condition achieved higher grades on a final test than their peers in the SR condition five months post- 
treatment [partially standardized $\beta=.25, p=.008, \mathrm{CIs}=0.045$ to 0.444 ]. Effects were consistent when controlling for initial test performance (i.e., when accounting for autoregressive effects). No AR (vs. SR) treatment effect was found for high elaborators $(p=.336)$.

Additional analyses probed the Treatment $\mathrm{x}$ Elaboration interaction employing a traditional approach that tested simple AR treatment effects within meaningful subgroups of students characterized by low ( $\leq-1$ SD below the median) or high $(\geq+1$ SD above the median) levels of elaboration. Simple $t$-tests were consistent with the above results. Low elaborators who received AR treatment $(n=98, M=77.39, S D=9.90)$ achieved final test grades that were nearly $5 \%$ higher than their SR treatment peers $(n=28, M=72.62, S D=12.18): t(255)=1.83, p=.035$, $d=0.39$. A Cohen's $d$ of 0.39 indicated that AR students outperformed SR students by $39 \%$ of a standard deviation on the final test. This effect size is small to moderate based on Cohen's conventions (1988) and noteworthy considering the treatment-treatment design. No treatment effect was observed for high elaborators $(p=.135)$. See Figure 2 for the Treatment $\mathrm{x}$ Elaboration interaction. $^{2}$

\section{Main Path Analysis}

A path analytic approach was employed to test whether AR treatment effects on academic performance were mediated by psychological process variables based on Weiner's attribution theory (1985a, 2012; see Figure 1). Note that residuals between the positive and negative achievement emotions were correlated to account for interrelationships between these constructs in accordance with previous research (e.g., Daniels et al., 2009; Hamm et al., 2016). The lavaan

\footnotetext{
${ }^{2}$ To extend initial evidence supporting the validity of the stress-reduction (SR) treatment (Parker, 2014), we conducted a supplemental Treatment $x$ Stress regression analysis that tested whether the SR (vs. AR) treatment was effective in reducing longitudinal stress for students experiencing elevated levels of stress in the first semester. As expected, the Treatment $x$ Stress interaction was significant $(\beta=.07, p=.018)$. Simple slope analyses showed that for students who experienced high levels of initial stress (at Time 1a), the SR (vs. AR) treatment predicted lower levels of longitudinal stress (at Time 2; partially standardized $\beta=.18, p=.040$, controlling for high school grade, age, and gender).
} 
package for R (Rosseel, 2012) was used to calculate the effects of predictor variables and assess model fit using chi-square $\left(\chi^{2}\right)$, the comparison fit index (CFI), and the root mean square error of approximation (RMSEA) based on recommendations by Byrne (2010). Results of these tests indicated that the model fit the data well, $\chi^{2}(12)=20.01, p=.067 ; \mathrm{CFI}=.994 ; \mathrm{RMSEA}=.029 .^{3}$

Individual path estimates (regression weights) revealed a pattern of results consistent with the proposed model (see Table 2). Note that the variables involved in the hypothesized interaction (treatment, cognitive elaboration) were mean centered to facilitate interpretation of their omnibus effects (Cohen et al., 2003). Treatment [partially standardized $\beta=-.17, p=.032$, $\mathrm{CIs}=-0.316$ to -0.015$]$ and the Treatment $\mathrm{x}$ Elaboration interaction $[\beta=.07, p=.039, \mathrm{CIs}=$ 0.004 to 0.141$]$ were significant predictors of the uncontrollable attributions.

The significant interaction was probed using lavaan (Rosseel, 2012) to examine AR treatment effects at low (-1 SD) and high (+1 SD) levels of cognitive elaboration. Consistent with the hypotheses, simple slope analyses showed that AR (vs. SR) reduced uncontrollable causal attributions four months post-treatment for only low elaborators [partially standardized $\beta$ $=-.33, p=.004, \mathrm{CIs}=-0.547$ to -0.104$]$. No treatment effects were observed for high elaborators $(p=.960)$. Only cognitive elaboration predicted the controllable attributions, suggesting that high elaborators tended to endorse more controllable attributions than low elaborators $(\beta=.13, p$ $<.001$, CIs $=0.063$ to 0.201$)$. Effects were consistent when controlling for baseline levels of each outcome measure (i.e., when adjusting for autoregressive effects of T1a uncontrollable and controllable attributions).

Supporting the proposed model, both uncontrollable and controllable attributions for poor performance were significant predictors of perceived control. Emphasizing uncontrollable

\footnotetext{
${ }^{3}$ Supplemental analyses corrected for unreliability in the study variables using a latent variable approach to structural equation modeling (Muthén \& Muthén, 1998-2015). Results supported the proposed model and were consistent with the pattern of findings reported in the main analyses.
} 
attributions was related to lower perceived control $(\beta=-.35, p<.001$, CIs $=-0.412$ to -0.294$)$, whereas emphasizing controllable attributions was related to higher perceived control $(\beta=.41, p$ $<.001$, CIs $=0.351$ to 0.468$)$. Results were consistent when accounting for autoregressive effects. Because AR predicted uncontrollable attributions (for low elaborators only) which in turn predicted perceived control, we tested whether the AR treatment had conditional indirect effects on perceived control via the uncontrollable attributions.

Conditional indirect treatment effects were tested at low (-1 SD) and high (+1 SD) levels of cognitive elaboration and tested for significance using a bootstrap approach that employed 95\% bias corrected confidence intervals (Hayes, 2013; Preacher \& Hayes, 2008). Mediation was confirmed if zero fell outside the confidence interval (CI) based on 5,000 samples of the unstandardized beta weights. The indirect effects of omnibus predictors were tested using the same bootstrap approach.

As expected, AR promoted perceived control through the uncontrollable attributions for only students with low levels of cognitive elaboration [partially standardized $\beta=.12$, CIs $=.113$ to .478]. This means that AR increased low elaborators' perceived control by $12 \%$ of a standard deviation by reducing their use of uncontrollable attributions. See Table 3 for a summary of indirect (mediated) effects which were consistent with the hypothesized model.

Emphasizing uncontrollable attributions was related to higher levels of negative emotion $[\beta=.18, p<.001, \mathrm{CIs}=0.110$ to 0.240$]$, whereas emphasizing controllable attributions was related to higher levels of positive emotion $[\beta=.12, p<.001$, CIs $=0.050$ to 0.186$]$. As expected, perceived control predicted both negative $[\beta=-.36, p<.001$, CIs $=-0.433$ to -0.291$]$ and positive emotion $[\beta=.27, p<.001, \mathrm{CIs}=0.196$ to 0.341$]$. Cognitive elaboration also influenced positive emotion $[\beta=.26, p<.001, \mathrm{CIs}=0.201$ to 0.325$]$. Effects were consistent when controlling for 
baseline (T1) levels of negative and positive emotion.

Supporting the model, increases in perceived control $[\beta=.08, p=.010$, CIs $=0.020$ to $0.145]$ and positive emotion $[\beta=.24, p<.001, \mathrm{CIs}=0.169$ to 0.302$]$ were related to better performance on the final test, whereas increases in negative emotion were related to worse performance $[\beta=-.18, p<.001, \mathrm{CIs}=-0.247$ to -0.107$]$. Results were consistent when controlling for initial test performance. See Figure 3 for a summary of AR's indirect effects on performance for low elaborators via the proposed sequence of psychological mechanisms.

\section{Discussion}

Our study shows that AR motivation treatments administered in online learning environments can improve performance for low elaborators who may struggle to adapt during school-to-university transitions. Considering that our pre-post, quasi-experimental field design involved an online SR treatment comparison condition (i.e., treatment vs. treatment design), rather than no treatment, the magnitude of AR's effect on performance is notable. Low elaborators in the AR condition outperformed their peers in the SR condition by nearly $5 \%$ on a final class test five months post-treatment $(M \mathrm{~s}=77.39 \mathrm{vs.} 72.62)$. The effect size of this difference $(d=.39)$ was small to moderate based on Cohen's (1988) conventions and ecologically relevant given that it translates into a full letter grade advantage (B vs. $\mathrm{C}+$ ) for AR recipients based on commonly used grading practices.

These findings advance the research literature on AR treatment efficacy. To date, laboratory and field studies have focused on evaluating the effectiveness of AR using randomized treatment versus no-treatment designs (see Perry et al., 2014; Perry \& Hamm, 2017). A recent meta-analysis by Lazowski and Hulleman (2016) revealed that such AR (vs. notreatment) effects are typically moderate in size $(d=0.54)$ and translate into performance gains 
of one to two letter grades (e.g., Perry et al., 2010). Results of our randomized treatment versus treatment field study support and extend this literature by showing that AR (vs. SR) had a small to moderate effect on two-semester performance $(d=0.39)$ that reflected a one letter grade boost for low elaborators. This suggests AR is not only an effective method to increase academic performance, but that it may be a more effective approach than treatments designed to reduce stress in competitive achievement settings.

Although the performance of low elaborators in AR condition was clearly better, the performance of their peers in the SR condition $(\mathrm{C}+)$ does not reflect an abject failure. Many students may even be satisfied with such passing grades that contribute to the completion of bachelor's degrees. However, there are negative consequences for those who intend to further their education. Bachelor's degrees were held in high esteem and provided entry to careers in many professions in the $20^{\text {th }}$ century. But degree inflation has reduced the value of bachelor's degrees, and entry to more advanced programs and careers such as law or medicine is contingent on exemplary academic performance at the undergraduate level (see Strenze, 2007). This makes a $\mathrm{C}+$ average a functional failure for those aspiring to gain admittance to professional or graduate programs and points to the potential long-term implications of the letter grade advantage observed for low elaborators in the AR condition (see Perry, Hladkyj, et al., 2001, 2005).

Our study also contributes to the AR literature by providing further support for the validity of AR treatment effects. The internal validity of AR motivation treatments were established in a series of early laboratory studies (e.g., Menec et al., 1994; Perry \& Magnusson, 1989; Perry \& Penner, 1990). Although quasi-experimental, randomized treatment field research supports the external and ecological validity of AR (e.g., Haynes et al., 2006; Perry et al., 2010), the procedures employed in these earlier AR field studies ignore modern educational realities 
encountered by college students who increasingly rely on digital technologies to learn course content (e.g., online learning environments). From a practical standpoint, the potential benefits of mass administering AR treatments online are considerable for university administrators, instructors, and students alike. Thus, our results provide additional support for the ecological validity of the treatment and suggest that AR treatments are scalable and can facilitate academic adaptation for students encountering challenging educational transitions.

\section{Theoretically-Derived Mediators and Attributional Retraining Efficacy}

Based on Perry et al.’s $(2014,2017)$ reviews of the extant research literature, this study is relatively unique in examining AR's indirect effects on performance through theory-derived mediators (cf., Weiner, 1985a, 2012). Results supported our hypotheses in that, for low (but not high) elaborators: (a) AR reduced the endorsement of uncontrollable attributions, (b) deemphasizing these maladaptive attributions promoted perceived control and emotional wellbeing, (c) enhanced perceived control predicted more positive and less negative emotion, and (d) perceived control and the emotions predicted academic performance. These findings advance the literature by systematically delineating AR's influence on performance via cognitive and affective process variables consistent with Weiner's attribution theory of motivation (1985a, 2012) for students who may be at risk of academic failure (low cognitive elaborators).

Several paths involving the AR motivation treatment are particularly noteworthy. For instance, we found that AR (vs. SR) reduced students' emphasis on uncontrollable attributions for achievement failure in Semester 2. This effect held when controlling for pre-treatment differences in students' Semester 1 causal attributions. These results extend previous research by showing that AR impacts students' causal attributions in achievement settings over a prolonged time period, even when pre-existing differences are accounted for (e.g., Hamm et al., 2014; Perry 
et al., 2010). Our results also expand on previous studies (Haynes et al., 2006; Parker et al., 2016) by documenting that AR indirectly enhances perceived control by reducing maladaptive causal attributions. In fact, students receiving AR reported perceived control levels that were $12 \%$ of a standard deviation higher than their peers in the SR condition as a consequence of AR reducing their endorsement of uncontrollable attributions (see Table 3). Thus, AR's influence on students' uncontrollable attributions had ramifications for their long-term perceived control.

Results indicated AR did not increase controllable attributions. However, this finding is consistent with research suggesting AR treatment effects on causal attributions can vary. AR can decrease students' emphasis on uncontrollable attributions (e.g., Hall et al., 2006), increase their emphasis on controllable attributions (e.g., Haynes et al., 2006), or potentially do both (e.g., Perry et al., 2010). Our results may, in part, be due to the fact that most students already emphasized controllable factors in explaining poor performance at Time 1a and Time 2 (respective $M \mathrm{~s}=14.82,15.30 ;$ possible range $=2-20$; actual range $=6-20)$. Considering the increased variability in students' endorsement of the uncontrollable attributions (respective Time 1a and Time $2 M \mathrm{~s}=21.23,21.26$; possible and actual range $=4-40$ ), these maladaptive causal explanations may have been more amenable to change. However, further research is needed to clarify relations between attribution content of AR treatments and their impact on controllable or uncontrollable attributions uniquely or in combination (see Perry \& Hamm, 2017).

Our results also have implications for Weiner's (1985a, 2012) attribution theory to the extent that researchers have yet to conduct a systematic test of his theorized attributioncognition-emotion-performance sequence in naturally occurring competitive achievement settings (see Reyna \& Weiner, 2001; Struthers, Miller, Boudens, \& Briggs, 2001; Struthers, Weiner, \& Allred, 1998; Van Overwalle et al., 1995; and Zhou \& Urhahne, 2013 for partial tests 
of this sequence). In this regard, several findings contribute to a more nuanced understanding of how attributional processes operate in such settings. First, our results are unique in demonstrating that a cognitive variable (perceived control) may play an important role in mediating the influence of controllable and uncontrollable attributions on positive and negative achievement emotions. Perceived control accounted for large proportions of the effects of controllable attributions on positive (48\%) and negative (88\%) emotion. Similarly, the influence of uncontrollable attributions on positive (90\%) and negative (40\%) emotion was chiefly accounted for by perceived control.

Second, the latter half of our model is unique in linking attributions to academic performance via cognitive and affective variables, thus providing support for an important tenet of Weiner's $(1985 \mathrm{a}, 2012)$ theory that has been largely neglected in past research. In fact, the indirect effects of controllable $(\beta=.12)$ and uncontrollable $(\beta=-.11)$ attributions on long-term achievement through perceived control and positive and negative achievement emotions were noteworthy. These effects suggest that adaptive changes in causal attributions have implications for long-term goal attainment due to their influence on theory-derived cognitions and emotions.

\section{Strengths, Limitations, and Future Directions}

One strength of this study was its reliance on the strong theoretical framework afforded by Weiner's $(1972,1985 a, 2012)$ attribution theory of motivation. The fundamental principles of Weiner's theory are clear, specific, testable, and supported by over 45 years of empirical evidence from replicated laboratory and field studies. Another strength was the use of an objective and ecologically-valid achievement outcome as a dependent measure, first-year students' performance on a final class test in a two-semester course (see Lazowski \& Hulleman, 2016; Richardson et al., 2012; Shadish et al., 2002; Tunnell, 1977). Such course grade measures 
represent authentic and consequential performance outcomes that predict future educational attainment $(r=.48)$ and occupational status ( $r=.33$; see Richardson et al., 2012; Strenze, 2007). Further, a pre-post, quasi-experimental, randomized treatment design was employed and autoregressive effects were accounted for. These procedures make causal inferences more viable than in research that fails to manipulate the independent variables or adjust for pre-existing differences in the dependent measures (Shadish et al., 2002). Our two-semester study design also enabled us to examine the long-term effects of an AR relative to an SR treatment, as measures were collected at three separate points during the academic year (November, March, April). Finally, our statistical approach, which involved combining moderated mediation and path analysis, allowed us to simultaneously examine how (attributions, perceived control, emotions) and for whom (low elaborators) AR impacted two-semester academic performance when controlling for high school grades, age, and gender.

One limitation in our study is that, although our specified model (see Figure 1) implies five different time points, data were collected in three phases. Thus, relationships between attributions, perceived control, and emotions were based on cross sectional data. However, our autoregressive regression analyses demonstrate that all paths in the model remain significant when controlling for pre-treatment differences in attributions, perceived control, emotions, and test performance. A second limitation concerns our measures of emotion. Weiner's (1985a, 2012) theory includes a rich array of attribution-related emotions that we were unable to fully capture (e.g., pride, self-esteem, hope, hopelessness, shame, guilt, anger, gratitude, sympathy, regret, schadenfreude, etc.). Hence, our study provides only a snapshot of the emotional complexity experienced by students in competitive achievement settings.

As described by Walton (2014) and Perry et al. (2014), psychologists have recently 
become reengaged with the importance and utility of motivation treatment interventions, and future research would do well to build on this line of inquiry. Perry et al.'s (2014) review outlines a three-phase evolution of theory-based AR motivation treatments administered to young adults in competitive achievement settings. The first (AR-performance linkage) and second (AR-attribution/cognition/emotion linkages) phases of this evolution are supported by well-controlled laboratory studies (documenting internal validity) and field studies featuring longitudinal, quasi-experimental, randomized treatment designs (documenting external and ecological validity).

Most relevant to future research, however, is the third phase (AR-attribution-cognitionemotion-performance sequence) that focuses on theoretically-derived psychological mediators of the AR-performance linkage which has received little attention thus far. Although the present study's longitudinal design and moderated mediation analytic approach provides initial support for the third phase, additional empirical evidence is needed. In particular, future studies should more rigorously test this sequence by examining the full array cognitions and emotions proposed by Weiner (e.g., responsibility, shame) as assessed at separate time points and over a longer period of time.

Recent technological advances offer opportunities to improve AR treatment procedures in terms of delivery and content. Regarding treatment delivery, our study provides initial evidence that AR interventions can be scaled up and mass delivered online. Further quasi-experimental randomized treatment field studies are needed to replicate and extend these findings using larger samples of students from geographically diverse universities. Regarding treatment content, new technologies could be leveraged to individualize AR treatments using self-regulation processes that require active cognitive engagement. One possibility entails incorporating personalized 
attribution information that shows AR recipients their pre-treatment attributional styles as a causal search activation or consolidation procedure. AR that involves such active engagement procedures may facilitate deeper processing of content tailored to each recipient and thereby boost treatment efficacy. Taken together, this implies online AR treatments could be personalized and delivered en masse as part of large-scale programs designed to facilitate educational success for first-year students in transition (cf. Robbins, Oh, Le, Button, 2009). 
Compliance with Ethical Standards

Funding: This study was supported by Social Sciences and Humanities Research Council of Canada (SSHRC) Doctoral and Postdoctoral Fellowships to J. M. Hamm, a SSHRC Insight Grant [435-2012-1143] and a Royal Society of Canada and Alexander von Humboldt research grant to R. P. Perry, and a SSHRC Operating Grant [410-2010-2049] to J. G. Chipperfield.

Ethical Approval: All procedures performed in studies involving human participants were in accordance with the ethical standards of the institutional and/or national research committee and with the 1964 Helsinki declaration and its later amendments or comparable ethical standards.

Informed consent: Informed consent was obtained from all individual participants included in the study. 


\section{References}

Alferes, V. R. (2012). Methods of randomization in experimental design. Thousand Oaks, CA: SAGE Publications.

Barefoot, B. O. (2004). Higher education's revolving door: Confronting the problem of student drop-out in U.S. colleges and universities. Open Learning, 19, 9-18.

Boese, G. D., Stewart, T. L., Perry, R. P., \& Hamm, J. M. (2013). Assisting failure prone individuals in navigating achievement based transitions using a motivation enhancing (Attributional Retraining) treatment. Journal of Applied Social Psychology. doi:10.1111/jasp.12139

Byrne, B. M. (2010). Structural equation modeling with AMOS: Basic concepts, applications, and programming ( $2^{\text {nd }}$ ed.). New York: Routledge, Taylor \& Francis Group.

Cameron, L. D., \& Nicholls, G. (1998). Expression of stressful experiences through writing: Effects of a self-regulation manipulation for pessimists and optimists. Health Psychology, 17, 84-92. doi:10.1037/0278-6133.17.1.84

Cohen, J. (1988). Statistical power analysis for the behavioral sciences. Hillsdale, NJ: Erlbaum.

Cohen, J., Cohen, P., West, S. G., \& Aiken, L. S. (2003). Applied multiple regression/correlation analysis for the behavioral sciences ( $3^{\text {rd }}$ ed.). London: Lawrence Erlbaum Associates.

Cook, T. D., \& Campbell, D. T. (1979). Quasi-experimentation: Design \& analysis issues for field settings. Boston: Houghton Mifflin.

Daniels, L. M., Stupnisky, R. H., Pekrun, R., Haynes, T. L., Perry, R. P., \& Newall, N. E. (2009). A longitudinal analysis of achievement goals: From affective antecedents to emotional effects and achievement outcomes. Journal of Educational Psychology, 101, 948-963. doi:10.1037/a0016096 
Directorate General for Education and Culture, European Commission (2015). Dropout and completion in higher education in Europe: Main report. Luxembourg City: Publications Office of the European Union.

Ellis, A. (1977). Reason and emotion in psychotherapy. Seacaucus, NJ: Lyle Stuart.

Ellis, A. (1985). How to live without anger. New York: Citadel Press.

Ellis, A. (2001). Feeling better, getting better, staying better: Profound self-help therapy for your emotions. Atascadero, CA: Impact Publishers.

Entwistle, N. (2000). Approaches to studying and levels of understanding: The influences of teaching and assessment. In J. Smart (Ed.), Higher education: Handbook of theory and research (Vol. 15, pp. 156-218). New York: Agathon Press.

Feldman, R. S. (2005). Improving the first year of college: Research and practice. Mahwah, NJ: Lawrence Erlbaum.

Hall, N. C., Hladkyj, S., Perry, R. P., \& Ruthig, J. C. (2004). The role of attributional retraining and elaborative learning in college students' academic development. Journal of Social Psychology, 144, 591-612. doi:10.3200/SOCP.144.6.591-612

Hall, N. C., Perry, R. P., Chipperfield, J. G., Clifton, R. A., \& Haynes, T. L. (2006). Enhancing primary and secondary control in achievement settings through writing-based attributional retraining. Journal of Social and Clinical Psychology, 25, 361-391. doi:10.1521/jscp.2006.25.4.361

Hall, N. C., Perry, R. P., Goetz, T., Ruthig, J. C., Stupnisky, R. H. \& Newall, N. E. (2007). Attributional retraining and elaborative learning: Improving academic development through writing-based interventions. Learning and Individual Differences, 17, 280-290. doi:10.1016/j.lindif.2007.04.002 
Hall, N. C., Perry, R. P, Ruthig, J. C., Haynes, T. L., and Stupnisky, R. H. (2005, April). Internet-based attributional retraining: Longitudinal effects on academic achievement in college students. American Educational Research Association, Montreal, QC.

Hamm, J. M., Perry, R. P., Chipperfield, J. G., Heckhausen, J., \& Parker, P. C. (2016). A motivation-enhancing treatment to sustain goal engagement during life course transitions. Motivation and Emotion, 40, 814-829. doi:10.1007/s11031-016-9576-4

Hamm, J. M., Perry, R. P., Chipperfield, J. G., Stewart, T. L., \& Heckhausen, J. (2015). Motivation-focused thinking: Buffering against stress-related physical symptoms and depressive symptomology. Psychology \& Health, 30, 1326-1345. doi:10.1080/08870446.2015.1050394

Hamm, J. M., Perry, R. P., Clifton, R. A., Chipperfield, J. G., \& Boese, G. D. (2014). Attributional retraining: A motivation treatment with targeted benefits for failure proneyoung adults in competitive achievement settings. Basic and Applied Social Psychology, 36, 221-237. doi:10.1080/01973533.2014.890623

Hayes, A. F. (2013). Introduction to mediation, moderation, and conditional process analysis: A regression-based approach. New York: The Guilford Press.

Haynes, T. L., Perry, R. P., Stupnisky, R. H., \& Daniels, L. M. (2009). A review of attributional retraining treatments: Fostering engagement and persistence in vulnerable college students. In J. Smart (Ed.), Higher education: Handbook of theory and research: Vol. 24 (pp. 227-272). The Netherlands: Springer Publishers.

Haynes, T. L., Ruthig, J. C., Perry, R. P., Stupnisky, R. H., \& Hall, N. C. (2006). Reducing the academic risks of over-optimism: The longitudinal effects of attributional retraining on cognition and achievement. Research in Higher Education, 47, 755-779. 
doi:10.1007/978-1-4020-9628-0_6

Haynes-Stewart, T. H., Clifton, R. A., Daniels, L., M., Perry, R., P., Chipperfield, J., G., \& Ruthig, J., C. (2011). Attributional retraining: Reducing the likelihood of failure, Social Psychology of Education, 14, 75-92. doi:10.1007/s11162-006-9014-7

Heckhausen, J., Wrosch, C., \& Schulz, R. (2010). A motivational theory of life-span development. Psychological Review, 117, 32-60. doi:10.1037/a0017668

Hulleman, C. S., Barron, K. E., Kosovich, J. J., \& Lazowski, R. A. (2016). Student motivation: Current theories, constructs, and interventions within an expectancy-value framework. In A. Lipnevich et al. (Eds.), Psychosocial Skills and School Systems in the $21^{\text {st }}$ Century (pp. 241-278). Switzerland: Springer International Publishing.

Lazowski, R. A., \& Hulleman, C. S. (2016). Motivation interventions in education: A meta analytic review. Review of Educational Research, 86, 602-640. doi:10.3102/0034654315617832

Lumley, M. A., \& Provenzano, K. M. (2003). Stress management through written emotional disclosure improves academic performance among college students with physical symptoms. Journal of Educational Psychology, 95, 641-649. doi:10.1037/00220663.95.3.641

Menec, V. H., Perry, R. P., Struthers, C. W., \& Schönwetter, D. J. (1994). Assisting at-risk college students with attributional retraining and effective teaching. Journal of Applied Social Psychology, 24, 675-701. doi:10.1111/j.1559-1816.1994.tb00607.x

Muthén, L. K., \& Muthén, B. O. (1998-2015). Mplus user's guide ( $7^{\text {th }}$ ed.). Los Angeles: Muthén \& Muthén.

OECD [Organization for Economic Co-operation and Development] (2012). Education today: 
The OECD perspective. OECD Publishing. doi:10.1787/edu_today-2013-en

Parker, P. C. (2014). Perceived control and treatment interventions in competitive achievement settings: Effects for students with relinquished control and fit-focused secondary control (Master's thesis). Retrieved from http://mspace.lib.umanitoba.ca.

Parker, P. C., Perry, R. P., Hamm, J. M., Chipperfield, J. G., \& Hladkyj, S. (2016). Enhancing the academic success of high-risk competitive student athletes using a motivation treatment intervention (attributional retraining). Psychology of Sport and Exercise, 26, 113-122. doi:10.1016/j.psychsport.2016.06.008

Pekrun, R., Goetz, T., Titz, W., \& Perry, R. P. (2002). Academic emotions in students'selfregulated learning and achievement: A program of quantitative and qualitative research. Educational Psychologist, 37, 91-106.

Pekrun, R., Hall, N. C., Goetz, T., \& Perry, R. P. (2014). Boredom and academic achievement: Testing a model of reciprocal causation. Journal of Educational Psychology, 106, 696710. doi:10.1037/a0036006

Pennebaker, J. W., Colder, M., \& Sharp, L. K. (1990). Accelerating the coping process. Journal of Personality and Social Psychology, 58, 528-537. doi:10.1037/0022-3514.58.3.528

Pennebaker, J. W., \& Francis, M. E. (1996). Cognitive, emotional, and language processes in disclosure. Cognition and Emotion, 10, 601-626. doi:10.1080/026999396380079

Perry, R. P. (2003). Perceived (academic) control and causal thinking in achievement settings: Markers and mediators. Canadian Psychologist, 44, 312-331. doi:10.1037/h0086956

Perry, R. P., Chipperfield, J. G., Hladkyj, S., Pekrun, R., \& Hamm, J. M. (2014). Attributionbased treatment interventions in some achievement settings. In S. Karabenick \& T. Urdan (Eds.), Advances in Motivation and Achievement (Vol. 18). Emerald Publishing. 
Perry, R. P., Hall, N. C., \& Ruthig, J. C. (2005). Perceived (academic) control and scholastic attainment in higher education. In J. C. Smart (Ed.), Higher education: Handbook of theory and research: Vol. 20 (pp. 363-436). The Netherlands: Springer.

Perry, R. P. \& Hamm, J. M. (2017). An attribution perspective on competence and motivation: Theory and treatment interventions. In A. Elliot, C. Dweck, \& D. Yeager (Eds.), Handbook of Competence and Motivation (2nd Edition): Theory and Applications (pp. 61-84). New York: Guilford Press.

Perry, R. P., Hladkyj, S., Pekrun, R. H., Clifton, R. A., \& Chipperfield, J. G. (2005). Perceived academic control and failure in college students: A three-year study of scholastic attainment. Research in Higher Education, 46, 535-569. doi:10.1007/s11162-005-3364-4

Perry, R. P., Hladkyj, S., Pekrun, R. H., \& Pelletier, S. T. (2001). Academic control and action control in the academic achievement of students: A longitudinal field study of selfregulation. Journal of Educational Psychology, 93, 776-789. doi:10.1037/00220663.93.4.776

Perry, R. P., \& Magnusson, J. L. (1989). Causal attributions and perceived performance: Consequences for college students' achievement and perceived control in different instructional conditions. Journal of Educational Psychology, 81, 164. doi:10.1037/00220663.81.2.164

Perry, R. P., \& Penner, K. S. (1990). Enhancing academic achievement in college students through attributional retraining and instruction. Journal of Educational Psychology, 82, 262-271. doi:10.1037/0022-0663.82.2.262

Perry, R. P., Schönwetter, D. J., Magnusson, J. L., \& Struthers, C. W. (1994). Students' explanatory schemas and quality of college instruction: Some evidence for buffer and 
compensation effects. Research in Higher Education, 35, 349-371.

doi:10.1007/BF02496828

Perry, R. P., \& Struthers, C. W. (1994, April). Attributional retraining in the college class-room: Some causes for optimism. Paper presented at the annual meeting of the American Educational Research Association, New Orleans, LA.

Perry, R. P., Stupnisky, R. H., Daniels, L. M., \& Haynes, T. L. (2008). Attributional (explanatory) thinking about failure in new achievement settings. European Journal of Psychology of Education, 23, 459-475. doi:10.1007/BF03172753

Perry, R. P., Stupnisky, R. H., Hall, N. C., Chipperfield, J. G., \& Weiner, B. (2010). Bad starts and better finishes: Attributional retraining and initial performance in competitive achievement settings. Journal of Social and Clinical Psychology, 29, 668-700. doi:10.1521/jscp.2010.29.6.668

Phan, H. P. (2010). Students' academic performance and various cognitive processes of learning: An integrative framework and empirical analysis. Educational Psychology: An International Journal of Experimental Educational Psychology, 30, 297-322. doi:10.1080/01443410903573297

Pintrich, P. R., Roeser, R. W., \& De Groot, E. A. M. (1994). Classroom and individual differences in early adolescents' motivation and self-regulated learning. Journal of Early Adolescence, 14, 139-161. doi:10.1177/027243169401400204

Pintrich, P. R., Smith, D. A., Garcia, T., \& McKeachie, W. J. (1993). Reliability and predictive validity of the motivated strategies for learning questionnaire (MSLQ). Educational and Psychological Measurement, 53, 801-813. doi:10.1177/0013164493053003024

Pintrich, P. R., Smith, D. A. F., \& McKeachie, W. J. (1989). A manual for the use of the 
Motivated Strategies for Learning Questionnaire (MSLQ). Ann Arbor, University of Michigan, School of Education, National Centre for Research to Improve Postsecondary Teaching and Learning.

Preacher, K. J., \& Hayes, A. F. (2008). Asymptomatic and resampling strategies for assessing and comparing indirect effects in multiple mediator models. Behavior Research Methods, 40, 879-891. doi:10.3758/BRM.40.3.879

Regehr, C., Glancy, D., \& Pitts, A. (2013). Interventions to reduce stress in university students: A review and meta-analysis. Journal of Affective Disorders, 148, 1-11. doi:10.1016/j.jad.2012.11.026

Reyna, C., \& Weiner, B. (2001). Justice and utility in the classroom: An attributional analysis of the goals of teachers' punishment and intervention strategies. Journal of Educational Psychology, 93, 309-319. doi:10.1037/0022-0663.93.2.309

Richardson, M., Abraham, C., \& Bond, R. (2012). Psychological correlates of university students' academic performance: A systematic review and meta-analysis. Psychological Bulletin, 138, 353-387. doi:10.1037/a0026838

Robbins, S. B., Lauver, K., Le, H., Davis, D., Langley, R., \& Carlstrom, A. (2004). Do psychosocial and study skill factors predict college out- comes? A meta-analysis. Psychological Bulletin, 130, 261-288. doi:10.1037/0033-2909.130.2.261

Robbins, S. B., Oh, I. S., Le, H., \& Button, C. (2009). Intervention effects on college performance and retention as mediated by motivational, emotional, and social control factors: Integrated meta-analytic path analyses. Journal of Applied Psychology, 94, 1163 1184. doi:10.1037/a0015738

Rosseel, R. (2012). lavaan: An R package for structural equation modeling. Journal of Statistical 
Software, 48(2), 1-36. doi:10.18637/jss.v048.i02

Shadish, W. R., Cook, T. D., \& Campbell, D. T. (2002). Experimental and quasi-experimental designs for generalized causal inference. Belmont, CA: Wadsworth Cengage Learning.

Snyder, T.D., \& Dillow, S.A. (2013). Digest of Education Statistics 2012 (NCES 2014-015). National Center for Education Statistics, Institute of Education Sciences, U.S. Department of Education. Washington, DC.

Strenze, T. (2007). Intelligence and socioeconomic success: A meta-analytic review of longitudinal research. Intelligence, 35, 401-426. doi:10.1016/j.intell.2006.09.004

Struthers, C. W., Miller, D. L., Boudens, C. J., \& Briggs, G. L. (2001). Effects of causal attributions on coworker interactions: A social motivational perspective. Basic and Applied Social Psychology, 23, 169-181.doi:10.1207/S15324834BASP2303_3

Struthers, C. W., Weiner, B., Allred, K. (1998). Effects of causal attributions on personnel decisions: A social motivational perspective. Basic and Applied Social Psychology, 20, 155-166. doi:10.1207/s15324834basp2002_7

Stupnisky, R. H., Stewart, T. L., Daniels, L. M., \& Perry, R. P. (2011). When do students ask why? Examining the precursors and outcomes of causal search among first-year college students. Contemporary Educational Psychology, 36, 201-211.

doi:10.1016/j.cedpsych.2010.06.004

Tinto, V. (2010). From theory to action: Exploring the institutional conditions for student retention (pp. 51-89, Vol. 25). In J. Smart (Ed.) Higher Education: Handbook of Theory and Research. New York: Springer Publishers.

Tunnell, G. B. (1977). Three dimensions of naturalness: An expanded definition of field research. Psychological Bulletin, 84, 426-437. doi:10.1037/0033-2909.84.3.426 
Van Overwalle, F., \& de Metsenaere, M. (1990). The effects of attribution-based intervention and study strategy training on academic achievement in college freshmen. British Journal of Educational Psychology, 60, 299-311. doi:10.1111/j.2044-8279.1990.tb00946.x

Van Overwalle, F., Mervielde, I., \& De Schuyter, J. (1995). Structural modelling of the relationships between attributional dimensions, emotions, and performance of college freshman. Cognition and Emotion, 9, 59-85. doi:10.1080/02699939508408965

Walton, G. M. (2014). The new science of wise psychological interventions. Current Directions in Psychological Science, 23, 73-82. doi:10.1177/0963721413512856

Weiner, B. (1972). Theories of motivation: From mechanism to cognition. Markham Publishers.

Weiner, B. (1985a). An attributional theory of achievement motivation and emotion. Psychological Review, 92, 548-573. doi:10.1037/0033-295X.92.4.548

Weiner, B. (1985b). “Spontaneous” causal thinking. Psychological Bulletin, 97, 74-84. doi:10.1037/0033-2909.97.1.74

Weiner, B. (1995). Judgments of responsibility: A foundation for a theory of social conduct. New York: Agathon Press.

Weiner, B. (2006). Social motivation, justice, and the moral emotions: An attributional approach. Mahwah, NJ: Lawrence Erlbaum Associates.

Weiner, B. (2012). An attribution theory of motivation. In Van Lange, P., Kruglanski, A., \& Higgins, T., (Eds.), Handbook of theories of social psychology. London: Sage.

Wilson, T. D., \& Linville, P. W. (1982). Improving the academic performance of college freshmen: Attribution therapy revisited. Journal of Personality and Social Psychology, 42(2), 367-376. doi:10.1037/0022-3514.42.2.367

Wong, P. T. P, \& Weiner, B. (1981). When people ask "why" questions, and the heuristics of 
attributional search. Journal of Personality and Social Psychology, 40, 650-663.

doi:10.1037/0022-3514.40.4.650

Zhou, J., \& Urhahne, D. (2013). Teacher judgment, student motivation, and the mediating effect of attributions. European Journal of Psychology of Education, 28, 275-295. 
Table 1

Summary of the Study Variables and Zero-Order Correlation Matrix

\begin{tabular}{|c|c|c|c|c|c|c|c|c|c|c|c|c|c|c|c|c|c|c|}
\hline & Variable & 1 & 2 & 3 & 4 & 5 & 6 & 7 & 8 & 9 & 10 & 11 & 12 & 13 & 14 & 15 & 16 & 17 \\
\hline 1. & T1a HSG & - & & & & & & & & & & & & & & & & \\
\hline 2. & T1a Pre-treatment performance & .43 & - & & & & & & & & & & & & & & & \\
\hline 3. & T1a Age & -.35 & -.09 & - & & & & & & & & & & & & & & \\
\hline 4. & T1a Gender & -.08 & .14 & .04 & - & & & & & & & & & & & & & \\
\hline 5. & T1a Cognitive elaboration & .11 & .16 & .04 & -.11 & - & & & & & & & & & & & & \\
\hline 6. & T1a UC. attributions & .03 & -.15 & -.04 & -.14 & .09 & - & & & & & & & & & & & \\
\hline 7. & T1a C. attributions & .06 & .09 & .06 & -.01 & .07 & .15 & - & & & & & & & & & & \\
\hline 8. & T1a Perceived control & .05 & .24 & .10 & .06 & .08 & -.31 & .32 & - & & & & & & & & & \\
\hline 9. & T1a Negative emotion & -.14 & -.44 & -.02 & -.11 & -.07 & .29 & -.05 & -.34 & - & & & & & & & & \\
\hline 10. & T1a Positive emotion & .08 & .42 & .04 & .09 & .31 & -.10 & .18 & .31 & -.46 & - & & & & & & & \\
\hline 11. & T2 Cognitive elaboration & .09 & .14 & -.04 & -.07 & .53 & .06 & .05 & .08 & -.09 & .29 & - & & & & & & \\
\hline 12. & T2 UC. attributions & .02 & -.14 & -.08 & -.15 & .06 & .48 & .04 & -.24 & .22 & -.08 & .05 & - & & & & & \\
\hline 13. & $\mathrm{~T} 2 \mathrm{C}$. attributions & .05 & .16 & .05 & -.06 & .15 & -.01 & .37 & .25 & -.11 & .20 & .19 & .12 & - & & & & \\
\hline 14. & T2 Perceived control & .16 & .30 & .07 & -.01 & .10 & -.26 & .25 & .54 & -.37 & .27 & .17 & -.30 & .39 & - & & & \\
\hline 15. & T2 Negative emotion & -.19 & -.45 & -.03 & -.03 & -.13 & .21 & -.05 & -.33 & .54 & -.35 & -.14 & .28 & -.16 & -.46 & - & & \\
\hline 16. & T2 Positive emotion & .16 & .45 & .03 & .08 & .31 & -.07 & .11 & .28 & -.38 & .60 & .37 & -.08 & .26 & .36 & -.53 & - & \\
\hline 17. & T3 Post-treatment performance & .42 & .66 & -.05 & .09 & .13 & -.08 & .08 & .27 & -.30 & .32 & .18 & -.10 & .16 & .31 & -.42 & .43 & - \\
\hline & $M$ & 7.90 & 66.79 & 1.21 & 1.36 & 21.05 & 21.23 & 14.82 & 17.03 & 6.33 & 13.22 & 21.20 & 21.26 & 15.30 & 16.82 & 6.42 & 13.39 & 78.20 \\
\hline & $S D$ & 1.57 & 13.72 & 0.41 & 0.48 & 4.47 & 6.72 & 3.34 & 2.27 & 4.12 & 3.45 & 4.32 & 6.82 & 3.23 & 2.48 & 4.16 & 3.63 & 13.73 \\
\hline
\end{tabular}

Note . HSG = high school grade. UC. attributions = uncontrollable attributions. C. attributions = controllable attributions. T1a $=$ Time 1a $($ Semester 1, November $)$.

$\mathrm{T} 2$ = Time 2 (Semester 2, March). T3 = Time 3 (Semester 2, April). 
Table 2

Summary of Individual Path Estimates (Regression Weights)

\begin{tabular}{|c|c|c|c|c|c|c|}
\hline \multirow[b]{2}{*}{ Predictor variables } & \multicolumn{6}{|c|}{ Outcome variables } \\
\hline & $\begin{array}{c}\text { UC. } \\
\text { attributions }\end{array}$ & $\begin{array}{c}\text { C. } \\
\text { attributions }\end{array}$ & $\begin{array}{l}\text { Perceived } \\
\text { control }\end{array}$ & $\begin{array}{l}\text { Negative } \\
\text { emotions }\end{array}$ & $\begin{array}{l}\text { Positive } \\
\text { emotions }\end{array}$ & $\begin{array}{c}\text { Academic } \\
\text { performance }\end{array}$ \\
\hline \multicolumn{7}{|l|}{ Treatment $x$ Elaboration $^{a}$} \\
\hline $\mathrm{AR}$ at low elaboration & $-.33^{*}$ & .01 & - & - & - & - \\
\hline AR at high elaboration & -.01 & -.02 & - & - & - & - \\
\hline Cognitive elaboration & .05 & $.13^{*}$ & .04 & $-.08^{*}$ & $.26^{*}$ & - \\
\hline UC. attributions & & & $-.35^{*}$ & $.18^{*}$ & -.01 & - \\
\hline C. attributions & & & $.41^{*}$ & -.02 & $.12^{*}$ & - \\
\hline Perceived control & & & & $-.36^{*}$ & $.27^{*}$ & $.08^{*}$ \\
\hline Negative emotions & & & & & & $-.18^{*}$ \\
\hline Positive emotions & & & & & & $.24^{*}$ \\
\hline
\end{tabular}

Note. $\mathrm{AR}=$ Attributional retraining. UC. attributions $=$ uncontrollable attributions. $\mathrm{C}$. attributions $=$ controllable attributions. Only path estimates specified in the structural model are shown (see Figure 1). Paths not specified are indicated by a dash (-). All estimates are adjusted for age, gender, and high school grade.

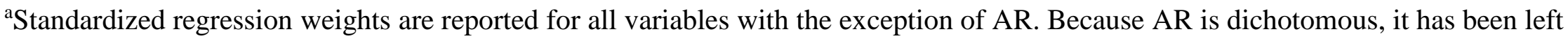
in its original metric $(1=\mathrm{SR}, 2=\mathrm{AR})$ to enable valid interpretation (Hayes, 2013).

${ }^{*} p \leq .05$ (two-tailed tests). 
Table 3

Tests of Indirect (Mediated) Effects

\begin{tabular}{lllcc}
\hline Predictor variables & Mediating variable(s) & Outcome variable & $\begin{array}{c}\text { Standardized } \\
\text { indirect effect }^{\mathrm{a}}\end{array}$ & $\begin{array}{c}95 \% \text { bias-corrected } \\
\text { CIs (lower, upper) }\end{array}$ \\
\hline $\begin{array}{c}\text { Treatment x Elaboration } \\
\text { AR at low elaboration }\end{array}$ & UC. attributions & Perceived control & $.12^{*}$ & $.113, .478$ \\
AR at high elaboration & UC. attributions & Perceived control & .00 & $-.187, .198$ \\
Cognitive elaboration & C. attributions & Perceived control & $.05^{*}$ & $.013, .048$ \\
UC. attributions & Perceived control & Negative emotions & $.13^{*}$ & $.057, .104$ \\
UC. attributions & Perceived control & Positive emotions & $-.10^{*}$ & $-.070,-.035$ \\
UC. attributions & Perceived control/emotions & Academic performance & $-.11^{*}$ & $-.291,-.149$ \\
C. attributions & Perceived control & Negative emotions & $-.15^{*}$ & $-.248,-.141$ \\
C. attributions & Perceived control & Positive emotions & $.11^{*}$ & $.085, .171$ \\
C. attributions & Perceived control/emotions & Academic performance & $.12^{*}$ & $.346, .674$ \\
Perceived control & Emotions & Academic performance & $.13^{*}$ & $.510, .953$ \\
\hline
\end{tabular}

Note. $\mathrm{AR}=$ Attributional retraining. UC. attributions $=$ uncontrollable attributions. $\mathrm{C}$. attributions = controllable attributions.

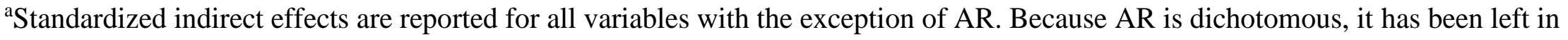
its original metric $(1=\mathrm{SR}, 2=\mathrm{AR})$ to enable valid interpretation (Hayes, 2013).

${ }^{\mathrm{b}}$ Confidence intervals are based on 5,000 samples of the unstandardized beta weights.

${ }^{*} p \leq .05$ based on unstandardized bias-corrected CIs (two-tailed tests). 


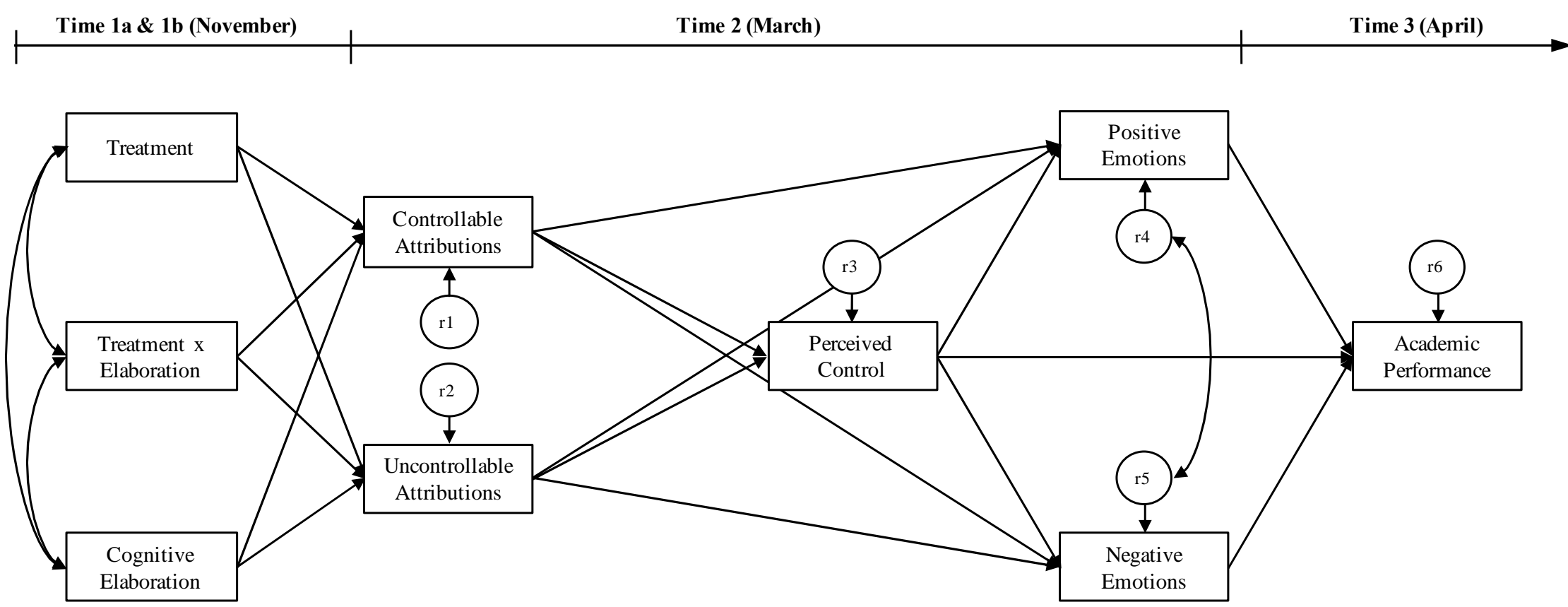

Figure 1. Structural model displaying specified paths for the hypothesized sequence. All effects were adjusted for high school grade, age, and gender. $r=$ residual. Paths from cognitive elaboration to perceived control and to positive and negative emotions were specified but are not shown to facilitate model presentation. 


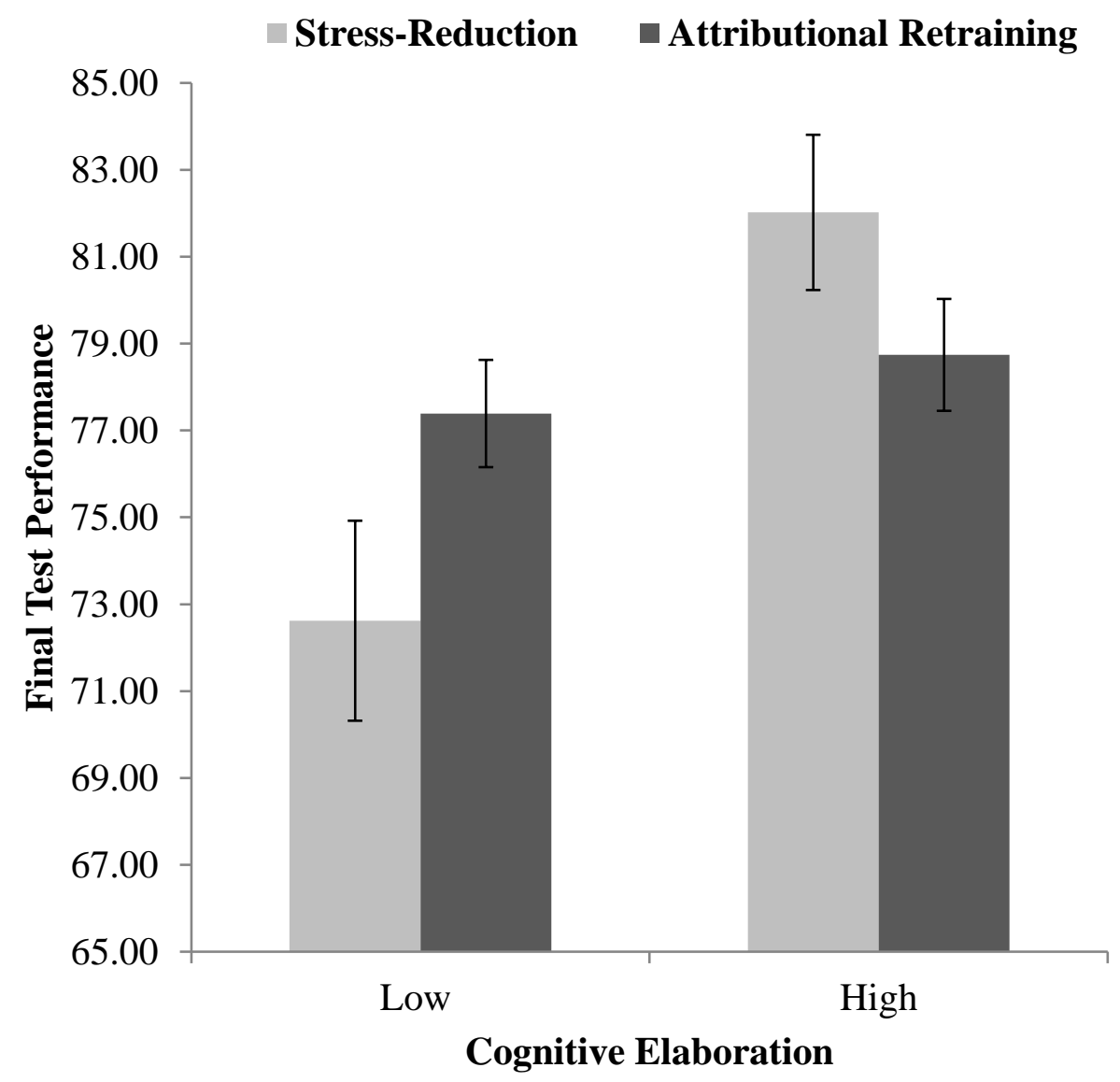

Figure 2. The Treatment x Elaboration interaction on Time 3 test performance. The effects of attributional retraining (vs. stress-reduction) are based on the subgroups analysis that distinguished low $(\leq-1 S D)$ and high $(\geq+1 S D)$ elaborators. Error bars represent \pm 1 standard error. 


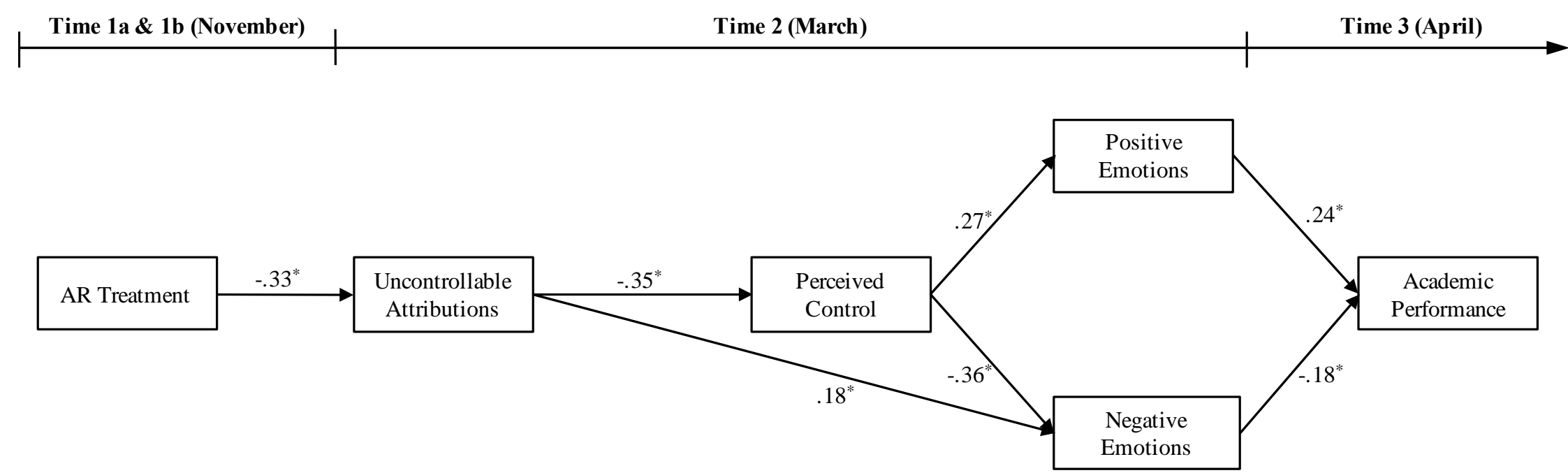

Figure 3. Indirect effects of attributional retraining (AR) on academic performance for low elaborators via significant paths in the proposed sequence of psychological mechanisms. Uncontrollable attributions included ability, teaching quality, test difficulty, and luck. Positive emotions included hope and pride, and negative emotions included helplessness and shame. All effects control for high school grade, age, and gender. Residuals and $\beta \mathrm{s}<.10$ are not shown. 